\title{
Investigando a legitimidade: estudo de atitudes de público em relação aos papéis do Estado e do mercado
}

\author{
Christina W. Andrews \\ Universidade Estadual Paulista "Júlio de Mesquita Filho"
}

\begin{abstract}
Resumo
Usando dados de nove países - Argentina, Brasil, Chile, República Tcheca, Polônia, Federação Russa, Finlândia, Alemanha e Estados Unidos - coletados pelo projeto World Values Survey, o artigo analisa a validade de quatro variáveis que potencialmente avaliam o nível de legitimidade do setor privado em relação ao setor público. Esta análise dá-se no contexto das discussões sobre o futuro das reformas prómercado, implementadas em diversos países nos últimos 20 anos. A investigação adotou uma estratégia em dois níveis: primeiramente, foram analisadas as freqüências agregadas por países e, em seguida, foram examinados os resultados de uma análise bivariada visando verificar a consistência interna das variáveis. $\mathrm{O}$ artigo conclui que as quatro variáveis consideradas não constituem uma dimensão capaz de avaliar a legitimidade do setor público versus a do setor privado.
\end{abstract}

Palavras-chave: legitimidade, cultura política, reformas pró-mercado, opinião pública

\section{Abstract}

Using data collected in nine countries - Argentina, Brazil, Chile, Czech Republic, Poland, Russian Federation, Finland, Germany and the USA - through the World Values Survey, the article analyses the validity of four variables with a supposed potential to evaluate the legitimacy level of the private sector vis-à-vis the public sector. This analysis in undertaken in the context of the discussions on the future of market reforms that were implemented in several countries in the past 20 years. The investigation adopted a two level strategy: first, the aggregated frequencies for the nine countries were analyzed, followed by a bivariate analysis aimed at verifying the internal consistency of the variables. The article concludes that the four variables under consideration do not compose a valid dimension capable of assessing the legitimacy of the public sector versus the private sector.

Key words: legitimacy, political culture, market reforms, public opinion 
Introdução $^{1}$

Os eventos históricos dos últimos 20 anos têm sido considerados um sinal do "fim da história" devido a sua aparente convergência em todo o mundo para um modelo econômico liberal e um sistema democrático (HUNTINGTON, 1991; FUKUYAMA, 1992). A era do "consenso keynesiano" foi substituída pela era do "consenso de Washington" (SINGER, 1997). Nas duas décadas que se seguiram à terceira onda de democratização dos anos 80, tanto países desenvolvidos como os em desenvolvimento implementaram reformas pró-mercado que intensificaram a participação do setor privado na provisão de serviços públicos. Na área da Administração Pública, a implementação do modelo da "administração gerencial" conhecido na literatura internacional como New Public Management - foi avaliada principalmente nos países anglo-saxões (ver GOW e DUFOUR, 2000; MAOR, 1999; LYNN, 1998; BROADBENT e LAUGHLIN, 1997; COHN, 1997; POLLITT, 1990). Por outro lado, nos países em desenvolvimento, pouco se sabe sobre o impacto das reformas gerenciais no processo de formulação de políticas públicas (ver, entretanto, MANNING, 2001). Para a América Latina, as avaliações têm se concentrado nos resultados das reformas estruturais, em especial nos supostos ganhos de eficiência dos programas de privatização e na estabilidade macroeconômica. Pouca atenção tem sido dada para questões envolvendo a legitimidade das reformas pró-mercado. Dependendo da perspectiva adotada, as opiniões podem variar consideravelmente. Segundo as organizações multilaterais, as reformas pró-mercado foram altamente bem sucedidas, ainda que tenham apresentado problemas na fase de implementação (INTERNATIONAL MONETARY FUND, 1999; NELLIS et al., 1999; WORLD BANK, 2005). Outros analistas, porém, são muito menos entusiastas em relação aos resultados das reformas neoliberais (HUBER e SOLT, 2004; PARKER e KIRKPATRICK, 2003).

Pesquisas de opinião pública recentes têm mostrado que o apoio às reformas pró-mercado tem decrescido nos países da América Latina (GRAHAM e SUKHTANKAR, 2004; LAGOS, 2004; LATINOBARÔMETRO, s.d.). No entanto, elas tendem a persistir nestes países. Weyland (2004) argumenta que o medo da hiperinflação, a influência de grupos de interesse poderosos e a pressão das organizações multilaterais devem manter os países da América latina dentro dos limites do status quo das economias neoliberais, pois, esses fatores tornam o custo político de mudanças excessivamente alto. Este autor conclui observando que:

\footnotetext{
${ }^{1}$ A autora agredece ao CESOP, na pessoa de Simone da Silva Aranha, o envio dos arquivos com os dados do World Values Survey. Uma versão anterior deste artigo foi apresentada no III Specialised International Conference, Public Administration and Private Enterprise: Co-operation, Competition and Regulation, Setembro de 2005.
} 
ANDREWS, C. W. Investigando a legitimidade.

"Dado o substancial e persistente apoio aos princípios de mercado e à ausência de alternativas viáveis, poucos cidadãos e ainda menos líderes políticos parecem estar dispostos a assumir tais riscos. Portanto, restrições estruturais e a persistência de atitudes prómercado parecem fortalecer-se mutuamente. Provavelmente, essa sinergia impedirá a emergência de desafios radicais ao novo esquema de desenvolvimento da América Latina em um futuro próximo." (WEYLAND, 2004, ênfases minhas, p. 313)

Entretanto, temos observado recentemente crises políticas e sociais em diversos países latino-americanos que resultaram em mudanças que se afastam do paradigma neoliberal na Argentina, Bolívia, Equador, Peru e Venezuela, por exemplo. O caso boliviano é emblemático, uma vez que a crise social que desencadeou as mudanças emergiu da reação popular contra a privatização de recursos naturais, como água, petróleo e gás natural. Por sua vez, a Argentina, ao reagir à profunda crise econômica de 2001, passou a rejeitar alguns dos ícones do modelo neoliberal e reintroduziu o controle do capital especulativo, um tipo de intervenção estatal considerada anátema até recentemente no país (PINHEIRO, 2005).

A opinião pública nas democracias desenvolvidas e nos países póscomunistas também tem indicado um desejo de mudança em relação ao status quo. A derrota no referendum para a ratificação da Constituição Européia na França e nos Países Baixos foi considerada uma rejeição à orientação neoliberal da Carta. Na Federação Russa, a partir de meados dos anos 90, pesquisas de opinião mostram um aumento de visões favoráveis ao velho regime e negativas da atual economia de mercado (SIL e CHEN, 2004).

Considerando a importância das pesquisas de opinião pública para a investigação do rumo das reformas pró-mercado em todo o mundo, o objetivo do presente trabalho é verificar a validade de um grupo de variáveis incluídas em pesquisas de opinião pública coordenadas pelo projeto do World Values Survey WVS. Como veremos adiante, este conjunto de variáveis aparentemente busca avaliar o nível de legitimidade de duas formas básicas de coordenação social: por meio do setor público ou por meio do setor privado. Nesse sentido, os dados coletados pelo WVS poderiam constituir um importante instrumento para avaliar o grau de legitimidade do setor privado vis-à-vis o setor público e suas implicações para o futuro das reformas pró-mercado em uma perspectiva comparada.

Antes da apresentação dos métodos empregados para a avaliação das variáveis do WVS e dos resultados da análise, apresentaremos uma breve discussão sobre os dois principais conceitos pertinentes a esta investigação: legitimidade e cultura política. 


\section{Legitimidade e cultura política}

Em um trabalho recente, Seligson, Booth e Gómez apresentaram uma detalhada discussão do conceito de legitimidade política e do uso de pesquisas de opinião pública como meio de avaliá-la empiricamente. Uma das questões levantadas pelos autores é o aparente paradoxo entre os resultados de pesquisas de opinião, que apontam para o declínio de legitimidade política nas democracias de países desenvolvidos, e a ausência de crises políticas: "Se a legitimidade de fato diminuiu muito, por que não tem havido protestos mais freqüentes e disseminados contra as democracias estabelecidas?" (SELIGSON, BOOTH e GÓMEZ, 2006, p. 3).

Mesmo os novos regimes democráticos têm se mostrado capazes de resistir a crises profundas. Essas questões apontam para a necessidade de verificar a validade dos instrumentos usados para avaliar a legitimidade política ou mesmo questionar a pertinência das teorias que apontam para o colapso dos regimes democráticos. Seligson et al. (2006) buscam responder a primeira dessas questões - ou seja, a validade dos instrumentos de avaliação da legitimidade política - por meio de uma análise de diversas variáveis freqüentemente utilizadas em pesquisas de opinião, tendo como referência um survey realizado na Costa Rica. Os autores observaram que a legitimidade política é constituída por várias dimensões, correspondendo, aproximadamente, àquelas já sugeridas por autores como Easton, Norris e Dalton: "existência de uma comunidade política", "desempenho do regime", "apoio (difuso e específico) às instituições do regime" e "apoio às autoridades do regime". Os autores também incluíram novas variáveis que resultaram em dimensões como "apoio aos princípios centrais do regime" e "apoio ao governo local". Em termos gerais, as dimensões encontradas apresentaram coerência interna e mostraram que estão correlacionadas umas às outras. A exceção foi a dimensão "apoio aos princípios centrais do regime", que apresentou apenas uma fraca associação com as demais dimensões. Os autores observaram que na Costa Rica

“[...] a legitimidade do regime está, em larga medida, desconectada da crença do cidadão nos princípios democráticos básicos. Esse resultado tem grande repercussão em nossas teorias da democracia e do papel dos valores democráticos" (SELIGSON et al., 2006, p. 25). 
ANDREWS, C. W. Investigando a legitimidade.

Eles concluem que a legitimidade de regime não seria tão importante para a legitimidade política quanto se supunha.

O conceito de legitimidade política se refere ao funcionamento das instituições políticas dos regimes democráticos, mas a legitimidade democrática pode se referir a questões mais amplas, como é o caso dos instrumentos que os governos têm a mão para a coordenação da sociedade. Deste modo, não só as instituições do regime democrático demandam legitimidade, mas também as políticas públicas que interferem na economia e no bem-estar social. Como observou Habermas (1998), instituições são mecanismos adotados pelas sociedades complexas para atribuir legitimidade a decisões políticas. No entanto, a complexidade social implica que nem todas as decisões políticas são efetivamente submetidas pelos canais de legitimação política, pois as organizações públicas também implementam políticas de forma autônoma, sem a interferência do legislativo. Além disso, o principal instrumento de regulação social das democracias contemporâneas são as leis, mas o sistema legal possui um caráter ambíguo: legalidade não implica necessariamente legitimidade. O funcionamento do sistema econômico, por exemplo, é regulado por leis, o que atribui ao mesmo uma aparência de legitimidade, sacramentando as injustiças distributivas e impedindo mudanças no status quo.

Muitas vezes, a lei fornece poder ilegítimo com a mera aparência de legitimidade. Em uma primeira observação, não se pode dizer se as regulamentações legais merecem o consentimento de cidadãos associados ou se resultam de uma auto-programação administrativa do poder social estruturado de tal maneira que [as regulamentações] geram de forma independente a necessária lealdade de massa (HABERMAS, 1998, p. 40, trad. por Andrews).

Em outras palavras, o funcionamento do sistema econômico e as decisões governamentais em relação a esse sistema não desfrutam automaticamente de legitimidade pelo fato de estarem legalizadas. Portanto, a demanda por um nível mais amplo de legitimidade continua latente no interior das democracias modernas por que alguns aspectos da coordenação social atuam além das instituições políticas formais.

A questão da "lealdade de massa" a que se refere Habermas leva a considerações sobre os limites de pesquisas de opinião na avaliação da legitimidade. Segundo o autor, a opinião pública expressaria, inter alia, a legitimidade das decisões políticas. Entretanto, ele alerta que seria necessário estabelecer uma distinção entre "opinião pública", entendida como um aspecto da esfera pública, e o resultado de pesquisas de opinião: 
"A opinião pública não é representativa no sentido estatístico do termo. Não é apenas um agregado de opiniões privadas coletadas individualmente de pessoas isoladas. Portanto, ela não deve ser confundida com resultados de pesquisas [de opinião]. Pesquisas de opinião oferecem certo reflexo da "opinião pública" somente se tiverem sido produzidas por meio de um debate público dirigido e por uma formação correspondente da opinião em uma esfera pública mobilizada." (HABERMAS, 1998, p. 362)

Assim sendo, se os debates públicos forem limitados por intervenções ideológicas ou falta de liberdade de expressão, ou ainda devido a um contexto social despolitizado (privatismo civil), as pesquisas de opinião pública não representarão opiniões legítimas. Daí a importância da liberdade de expressão e de fóruns para o debate público na formação de uma verdadeira opinião pública. A independência da opinião pública das instituições políticas formais é um importante elemento das democracias modernas. Ainda que as instituições políticas sejam necessárias para atribuir legitimidade às decisões políticas, elas não podem transformar a si próprias: a mudança política depende em última instância em uma esfera pública politizada e capaz de exercer pressão sobre as instituições formais (HABERMAS, Ibid.).

O conceito de legitimidade política discutido por Seligson et al. (2006) se baseia somente no apoio às instituições democráticas e no desempenho dos governantes, negligenciando o papel da esfera pública nos regimes democráticos. Tendo em mente esta concepção mais ampla dos sistemas democráticos, pode-se encontrar uma explicação para o paradoxo mencionado pelos autores: o declínio da legitimidade política (confiança nas instituições democráticas) não sinaliza necessariamente para o colapso das democracias, mas pode estar indicando a necessidade de reforma das instituições políticas.

Apesar das limitações pertinentes às pesquisas de opinião mencionadas, consideraremos que as mesmas refletem adequadamente a "opinião pública" nos países democráticos uma vez que esteja garantida a liberdade de expressão (inclusive uma imprensa independente). Portanto, os dados obtidos por meio de pesquisas de opinião podem ser úteis para a discussão da legitimidade do setor privado vis-à-vis o setor público.

Outro aspecto teórico que devemos abordar aqui é a idéia de "cultura política". Os autores que adotam esta perspectiva teórica sustentam que o regime democrático resulta de uma "cultura cívica" específica, ou seja, um conjunto de valores sobre o convívio na comunidade política que são compartilhados pela população. Segundo o trabalho clássico de Almond e Verba (1963), uma cultura política capaz de sustentar regimes democráticos exigiria cidadãos que 
ANDREWS, C. W. Investigando a legitimidade.

demonstrassem alto nível de confiança interpessoal, tolerância e engajamento cívico. Por sua vez, Inglehart (1988), em um estudo no qual utilizou uma análise de regressão multivariada, afirmou que os regimes democráticos são gerados em uma cultura política caracterizada por altos níveis de satisfação pessoal, satisfação política e confiança interpessoal, e também pela rejeição a mudanças políticas revolucionárias. Posteriormente, Putnam et al. (1993) apresentaram um conceito de "capital social" que difere substancialmente daquele introduzido anteriormente por Bourdieu (1985). Para os primeiros, "capital social" corresponde à presença em comunidades, ou mesmo na sociedade mais ampla, de altos níveis de confiança interpessoal e engajamento cívico, substrato necessário não só para a consolidação das instituições democráticas, mas também para o desenvolvimento econômico. 0 conceito de "capital social" desenvolvido por Putnam et al. alcançou grande repercussão dentro e fora dos meios acadêmicos, tendo sido difundido principalmente pelo Banco Mundial e pela Organização para a Cooperação e o Desenvolvimento Econômico - OCDE. Apesar desta influência, o conceito putnamiano de "capital social" não está imune a críticas: Ponthieux (2004) considera-o obscuro e redundante, enquanto Fine (2003) acusa o Banco Mundial de usá-lo como uma estratégia para transferir o enfrentamento dos problemas sociais do Estado para a "sociedade civil".

O próprio conceito de cultura política tem sido questionado por alguns autores. Seligson (2002) argumenta que os valores cívicos identificados por Inglehart (1988) não constituem uma "cultura" de fato. Para tanto, seria necessário que existisse uma correlação linear entre as variáveis culturais (valores cívicos) no nível individual e não apenas uma correlação entre essas variáveis e a variável dependente "regime político" nos dados agregados por país. Usando as mesmas variáveis analisadas por Inglehart, Seligson demonstrou que a correlação linear entre valores cívicos e democracia de fato existia no nível macro. Entretanto, as variáveis indicadoras de valores cívicos não apresentavam uma correlação linear no nível individual: indivíduos que apresentavam altos níveis de confiança interpessoal não eram particularmente inclinados a expressar oposição a mudanças revolucionárias, nem tendiam a expressar maiores níveis de satisfação pessoal ou política, seja nas democracias consolidadas ou nos países em processo de democratização. Seligson acusou Inglehart de ter cometido uma "falácia ecológica", isto é, de ter atribuído uma tendência observada no nível macro para o nível individual, concluindo que não há comprovação empírica da "síndrome de cultura cívica" sugerida por Inglehart (1988).

Inglehart e Wezel contra-atacaram a acusação de Seligson, dizendo que este teria sucumbido à "falácia individualista", ou seja, atribuído uma tendência individual para o nível macro. Segundo os primeiros, as "associações no nível agregado freqüentemente têm mais impacto em fenômenos sociais do que aquelas 
no nível individual" (INGLEHART e WEZEL, 2003, p. 7) e que "é a tendência de massa nas atitudes [individuais] que conta, não a estrutura de atitudes no nível individual" (Idem, p. 10). Aparentemente, esses argumentos parecem razoáveis. Mas serão mesmo? Para tanto, seria necessário refletir sobre o significado da palavra "cultura". Pode-se dizer que este pode ser compreendido por meio do conceito de "mundo da vida", definido como o conjunto de sentidos que atores compartilham e adotam para interpretar o mundo (HABERMAS, 1984). Neste sentido, opiniões formam a uma "cultura" à medida que são compartilhadas pela maioria dos indivíduos de uma dada sociedade. Se atitudes ou valores não são compartilhadas no nível individual - ou seja, se não há intersubjetividade em relação a esses valores -, então, não há uma "cultura" que mereça essa designação.

Portanto, parece que Seligson (2002) tem um forte argumento: se as variáveis que pretendem detectar a existência de uma "síndrome de cultura cívica" não estão associadas no nível individual, então, ou essas variáveis são inapropriadas para expressar o fenômeno ou todo o conceito de cultura cívica deveria ser revisto. Uma perspectiva similar pode ser aplicada à discussão sobre a legitimidade de orientações pró-mercado ou pró-Estado. Pode-se falar de uma "síndrome de cultura pública" ou de uma "síndrome de cultura privada"?

Investigando a legitimidade do setor público em relação ao setor privado

A maior parte dos estudos comparativos internacionais que utiliza pesquisas de opinião pública tem se limitado a regiões específicas ou a um grupo de países com níveis similares de desenvolvimento (MEHRTENS III, 2004; CARRERA, CHECCHI e FLORIO, 2004). No entanto, a preferência por estudos comparativos entre países de mesmo nível de desenvolvimento limita o alcance das respostas sobre o fenômeno em estudo. Bunce (2000) argumentou que estudos comparados sobre a democracia e democratização devem abandonar o desenho de pesquisa baseado em sistemas similares e adotar um desenho fundamentado em sistemas diferentes. Seguindo esta sugestão, adotarei aqui um desenho de estudo de caso comparativo entre países com diferentes níveis de desenvolvimento econômico. Meu objetivo é identificar a validade de um grupo de variáveis do WVS como possíveis indicações da legitimidade do setor privado em relação ao setor público.

Os dados utilizados para a presente investigação incluem nove países que compõem três grupos distintos: (a) Argentina, Brasil e Chile - países latinoamericanos que passaram por reformas pró-mercado nos últimos 20 anos, embora com intensidades diferentes; (b) Federação Russa, Polônia e República Tcheca países que integraram o bloco soviético e que estão vivenciando a transição para 
ANDREWS, C. W. Investigando a legitimidade.

economias de mercado; e (c) Finlândia, Alemanha e Estados Unidos, nações desenvolvidas classificadas por Esping-Andersen (1990) como Estados de bem-estar social dos tipos social-democrata, conservador e liberal, respectivamente.

A Tabela 1 apresenta as quatro variáveis do questionário do World Values Survey que se referem às atitudes pró-mercado ou pró-Estado. Estas variáveis também podem ser interpretadas segundo a tipologia dos "três mundos" de bem. estar social desenvolvida por Esping-Andersen (1990). Como argumentou o autor, países capitalistas desenvolvidos podem ser classificados de acordo com a ênfase que atribuem para a igualdade social e a intervenção estatal. Estados de bem-estar social do tipo social-democrata enfatizam a igualdade (variável V141) e têm o maior nível de intervenção estatal (variável V142); em países como a Suécia e a Finlândia, a visão predominante é que o Estado deve ser o provedor das necessidades básicas de cada um, independentemente da posição social dos cidadãos (variável V143). Esses países têm uma visão positiva da intervenção estatal e não confiam no mercado como o mecanismo coordenador da sociedade (variáveis V142 e V144). Por outro lado, em países de bem-estar social do tipo liberal, como os Estados Unidos, a ética do trabalho predomina sobre a igualdade social (variável V141). Neste caso, há uma ênfase na responsabilidade individual (variável V143) e o mercado é visto sob uma ótica favorável para o bem-estar da sociedade (V114). Os estados de bem-estar social do tipo conservador, como a Alemanha, estariam em uma posição intermediária em relação aos estados de bem-estar social do tipo social-democrata e liberal. Nesses países, há um acordo generalizado de que o Estado deveria ser o provedor de benefícios sociais amplos, como aposentadorias (variável V143), mas há menor ênfase na igualdade social (variável V141), devido a sua estrutura corporativa. Além disso, nos Estados de bem-estar social do tipo conservador, a família, não o Estado, é que deve desempenhar o principal papel na provisão de redes de seguridade para mulheres e crianças (variável V143). De todo o modo, a interpretação mais ampla das quatro variáveis se refere ao tipo e grau de intervenção do Estado em questões sociais e econômicas e, portanto, poderia servir como instrumentos para uma avaliação da legitimidade de políticas que enfatizam a coordenação social através do Estado ou do mercado. 
Tabela 1

Atitudes pró-Estado e pró-mercado, segundo variáveis do World Values Survey

\begin{tabular}{|l|c|l|}
\hline $\begin{array}{l}\text { V141 - A renda deve ser mais bem } \\
\text { distribuída }\end{array}$ & $\mathrm{X}$ & $\begin{array}{l}\text { Precisamos de uma maior diferença na } \\
\text { renda para incentivar o esforço individual. }\end{array}$ \\
\hline $\begin{array}{l}\text { V142 - A propriedade privada dos negócios } \\
\text { deve ser aumentada }\end{array}$ & $\mathrm{X}$ & $\begin{array}{l}\text { A propriedade governamental dos negócios } \\
\text { e da indústria deve ser aumentada }\end{array}$ \\
\hline $\begin{array}{l}\text { V143 - 0 governo deve assumir maior } \\
\text { responsabilidade para garantir que todos } \\
\text { tenham suas necessidades atendidas. }\end{array}$ & $\mathrm{X}$ & $\begin{array}{l}\text { As pessoas devem assumir maior } \\
\text { responsabilidade para suprir suas } \\
\text { necessidades. }\end{array}$ \\
\hline $\begin{array}{l}\text { V144 - A competição é positiva. Ela estimula } \\
\text { as pessoas a trabalhar duro e desenvolver } \\
\text { novas idéias. }\end{array}$ & $\mathrm{X}$ & $\begin{array}{l}\text { A competição é negativa. Ela faz surgir o } \\
\text { que há de pior nas pessoas. }\end{array}$ \\
\hline
\end{tabular}

A análise dos dados desenvolve-se, inicialmente, segundo a perspectiva macro, verificando-se as freqüências das variáveis agregadas por país. Em seguida, os dados são analisados segundo a perspectiva micro (individual), verificando-se a consistência interna das variáveis. Esta análise indicará se as quatro variáveis do WVS podem ser interpretadas como componentes de uma única dimensão capaz de indicar tendências de opinião pública favoráveis à coordenação da sociedade pelo Estado ou pelo mercado. Caso essa dimensão possa ser identificada, seria possível identificar em diferentes países as hipóteses da "síndrome de cultura privada" da "síndrome de cultura pública". No primeiro caso, isso fortaleceria a tese de continuidade das reformas pró-mercado; no segundo, seria um sinal da perda de legitimidade das políticas neoliberais, o que favoreceria tendências a mudanças na direção de um Estado mais intervencionista em questões econômicas e sociais.

Cabe destacar que os dados usados nesta análise foram coletados, na maioria dos casos, na década de 1990; no caso do Brasil, os dados foram coletados em 1997, antes, portanto, de concluídas as principais privatizações da primeira administração do presidente Fernando Henrique Cardoso (1994-1998). Assim sendo, os resultados da pesquisa utilizados aqui não expressam as conseqüências das privatizações realizadas no Brasil e em outros países latino-americanos. No entanto, entende-se que a cultura política de um país é formada ao longo de muitos anos, sinalizando não só as características do passado recente, mas também as tendências no futuro próximo. Daí a relevância de variáveis capazes de expressar uma possível "síndrome" de longo prazo, seja favorável à coordenação social pelo 
ANDREWS, C. W. Investigando a legitimidade.

Estado, seja favorável à coordenação pelo mercado. De todo o modo, o objetivo deste trabalho é verificar a existência de uma dimensão que expresse essas possíveis tendências de cultura política. Assim sendo, mesmo considerando que os dados não são recentes, é possível utilizá-los para verificar a consistência das variáveis, tanto no nível macro como no nível micro.

No Gráfico 1 são apresentados os resultados das freqüências agregadas para os nove países incluídos na análise. As escalas das variáveis V142 e V 144 foram invertidas para padronizar o sentido de orientação das respostas (pró-Estado ou pró-mercado) e os resultados foram agregados de forma a apresentarem resultados dicotômicos: as respostas de 1 a 5 na escala correspondem às freqüências relativas à "orientação para o setor privado" e as respostas de 6 a 10 correspondem às freqüências relativas à "orientação para o setor público".

Como se pode observar, os dados referentes aos três países desenvolvidos não são capazes de discriminar os países segundo a tipologia de Esping-Andersen (1990). Apenas nos Estados Unidos as quatro variáveis apresentam consistência em relação ao tipo "liberal", mas $44 \%$ da população considera necessário diminuir a desigualdade de renda. No caso da Alemanha, embora a variável sobre a igualdade/desigualdade de renda não esteja disponível, é possível considerar que, em geral, os dados são consistentes com o tipo de Estado de bem-estar social "conservador". Neste caso, a maioria da população tende a concordar com a afirmação de que o indivíduo deve assumir uma maior responsabilidade no atendimento de suas necessidades básicas. A Finlândia, por outro lado, não se apresenta como um típico país social-democrata, pois seria esperado que a variável sobre a responsabilidade na provisão de necessidades básicas expressasse uma orientação para o setor público. 


\section{Gráfico 1}

Freqüências agregadas para as variáveis da Tabela 1

\section{Orientação para o setor público \\ Orientação para o setor privado}

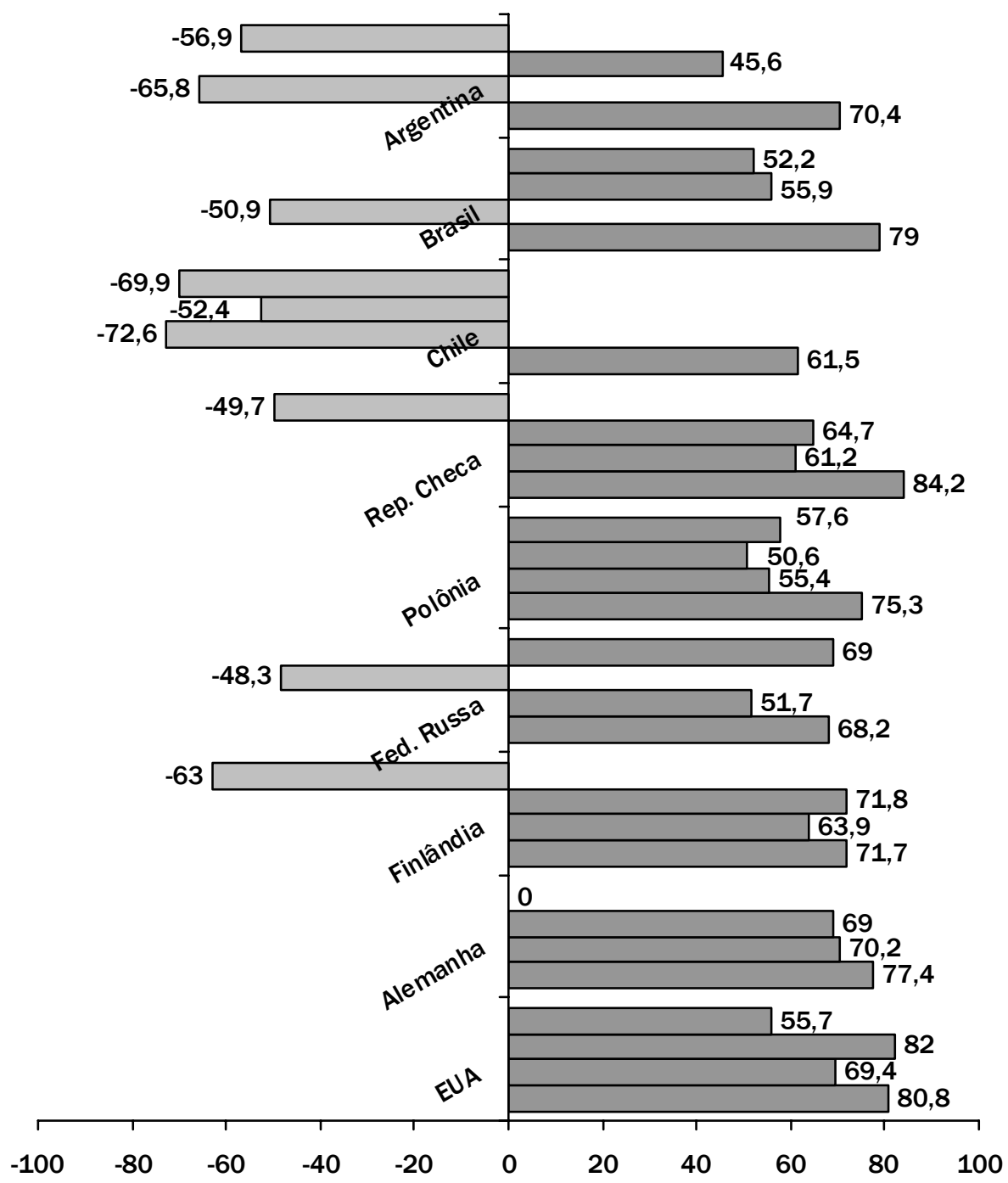

Fonte: European Values Study Group and World Values Survey Association (2004).

Pergunta: "Agora eu gostaria que você me dissesse sua visão sobre várias questões. Como você localizaria a sua visão nesta escala? 1 quer dizer que você concorda completamente com a afirmação à esquerda; 10 significa que você concorda completamente com a visão à direita, e se a sua posição está em algum lugar entre estas duas afirmações, você pode escolher qualquer número entre 1 e 10."

$\mathrm{N}$ : Argentina = 1.280 (1999); Brasil = 1.149 (1997); Chile = 1.200 (2000); Rep. Checa = 1.908 (1999); Polônia = 1.095 (1999); Federação Russa. = 2.500 (1999); Finlândia = 1.038 (2000); Alemanha = 2.036 (1999); EUA = 1.200 (1999). 
ANDREWS, C. W. Investigando a legitimidade.

Os países pós-comunistas não apresentam um padrão comum de respostas. A Polônia mostra uma orientação para o setor privado em todas as quatro variáveis; a República Tcheca apresenta uma orientação para o setor público para a variável sobre renda (V141), e a maioria dos respondentes da Federação Russa tende a concordar com a afirmação de que a propriedade governamental dos negócios deveria aumentar (V142). Um padrão diversificado também emerge dos resultados relativos aos países latino-americanos. O Chile apresenta uma orientação claramente direcionada para o setor público; no Brasil predomina uma orientação para o setor privado e a Argentina aparece em uma posição intermediária. Cabe notar que todos os países apresentaram uma orientação para o setor privado no que se refere à variável sobre competição (V114).

Os resultados da análise no nível macro confirmam os resultados obtidos por Mehrtens III (2004). O autor, utilizando as quatro variáveis do WVS já citadas e outras obtidas de diferentes surveys provenientes de 18 países, procurou verificar a relação entre a opinião pública e os três tipos de Estado de bem-estar social propostos por Esping-Andersen (1990). Os resultados mostraram apenas uma fraca correlação entre a opinião pública e os três tipos de Estado de bem-estar social. As análises de regressão multivariada e as correlações bivariadas permitiram distinguir entre os Estados de bem-estar social do tipo "liberal", de um lado, e os do tipo "conservador" e "social-democrata", de outro, mas não foram capazes de separar os dois últimos tipos. Os casos da Suécia e do Reino Unido foram considerados anômalos: o primeiro seria mais "liberal" e o último mais "social-democrata" do que o previsto pela tipologia de Esping-Andersen. Assim, embora a tipologia dos "três mundos" tenha sido confirmada quando as variáveis utilizadas são as políticas públicas efetivamente adotadas (POWELL e BARRIENTOS, 2004), ela não é claramente verificada por meio das variáveis originadas de pesquisas de opinião pública.

Tendo como referência os resultados da análise no nível macro, podemos chegar a conclusões adicionais. Em primeiro lugar, os resultados referentes aos três países latino-americanos não indicam um "substancial e persistente apoio aos princípios de mercado" como pressuposto por Weyland (2004). Nos países póscomunistas, também não se pode concluir por um inequívoco apoio ao setor privado. $O$ fato de que todos os nove países incluídos na análise apresentam uma orientação pró-mercado no que se refere à variável sobre a competição (V144) deve ser interpretado com cautela. De fato, as variáveis utilizadas pelo WVS se mostram ambíguas no que se refere a aspectos específicos das reformas pró-mercado, uma vez que não mencionam especificamente a opinião em relação a políticas associadas ao modelo, como as privatizações. Uma comparação com os dados 
secundários da pesquisa elaborada pelo Latinobarômetro pode ajudar a esclarecer esse aspecto ${ }^{2}$.

Uma vez que os programas de privatização foram implementados em praticamente todos os países latino-americanos, perguntas específicas sobre a avaliação desses programas foram incluídas nas pesquisas mais recentes do instituto. O Gráfico 2 apresenta os resultados do Latinobarômetro para os anos de 2002 e 2003 referentes à seguinte pergunta: "Você concorda fortemente, concorda parcialmente, discorda parcialmente ou discorda fortemente com a seguinte sentença: 'A privatização de empresas estatais foi benéfica para o país.' O Gráfico 3 apresenta os resultados do Latinobarômetro de 2003 para outra pergunta relacionada aos programas de privatização: "Serviços públicos como água, eletricidade, foram privatizados. Considerando preço e qualidade, você diria que está muito mais satisfeito, mais satisfeito, menos satisfeito ou muito menos satisfeito do que você estava antes com esses serviços?"

\footnotetext{
${ }^{2}$ O Latinobarômetro é um instituto de pesquisas de opinião sediado no Chile que realiza todos os anos pesquisas de opinião pública em 18 países latino-americanos que abordam questões políticas, comportamentais e sociais
} 


\section{Gráfico 2}

Opinião positiva sobre a privatização de empresas estatais para países latino-americanos, 2003-2004

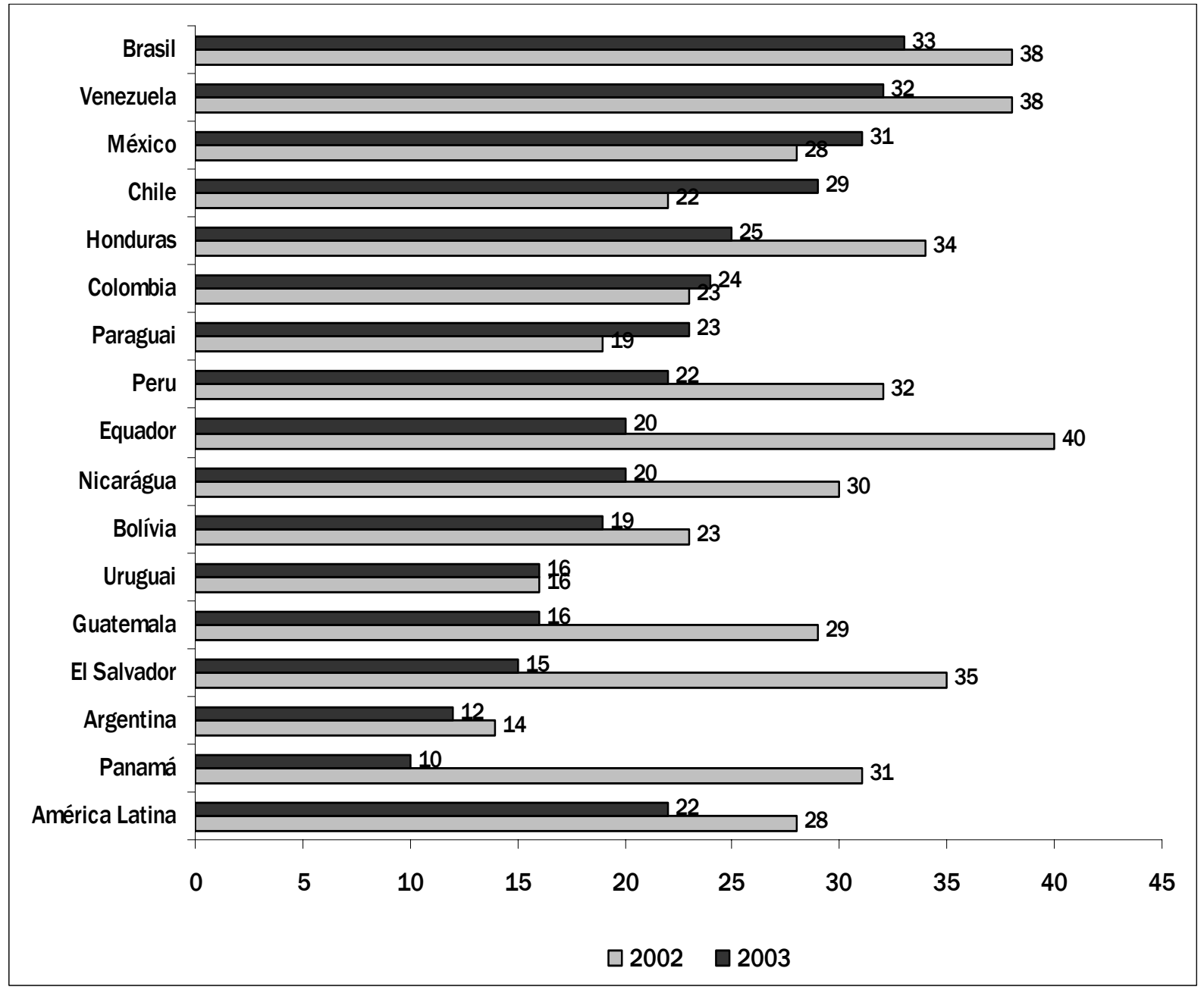

Fonte: Latinobarómetro 2002-2003, citado por Lagos (2004)

Pergunta: "Você concorda fortemente, concorda parcialmente, discorda parcialmente ou discorda fortemente com a seguinte sentença: 'A privatização de empresas estatais foi benéfica para o país. '" (\% respostas "concorda fortemente" e "concorda parcialmente") 


\section{Gráfico 3}

Nível de satisfação com a privatização dos serviços públicos, em países latino-americanos, 2003-2004

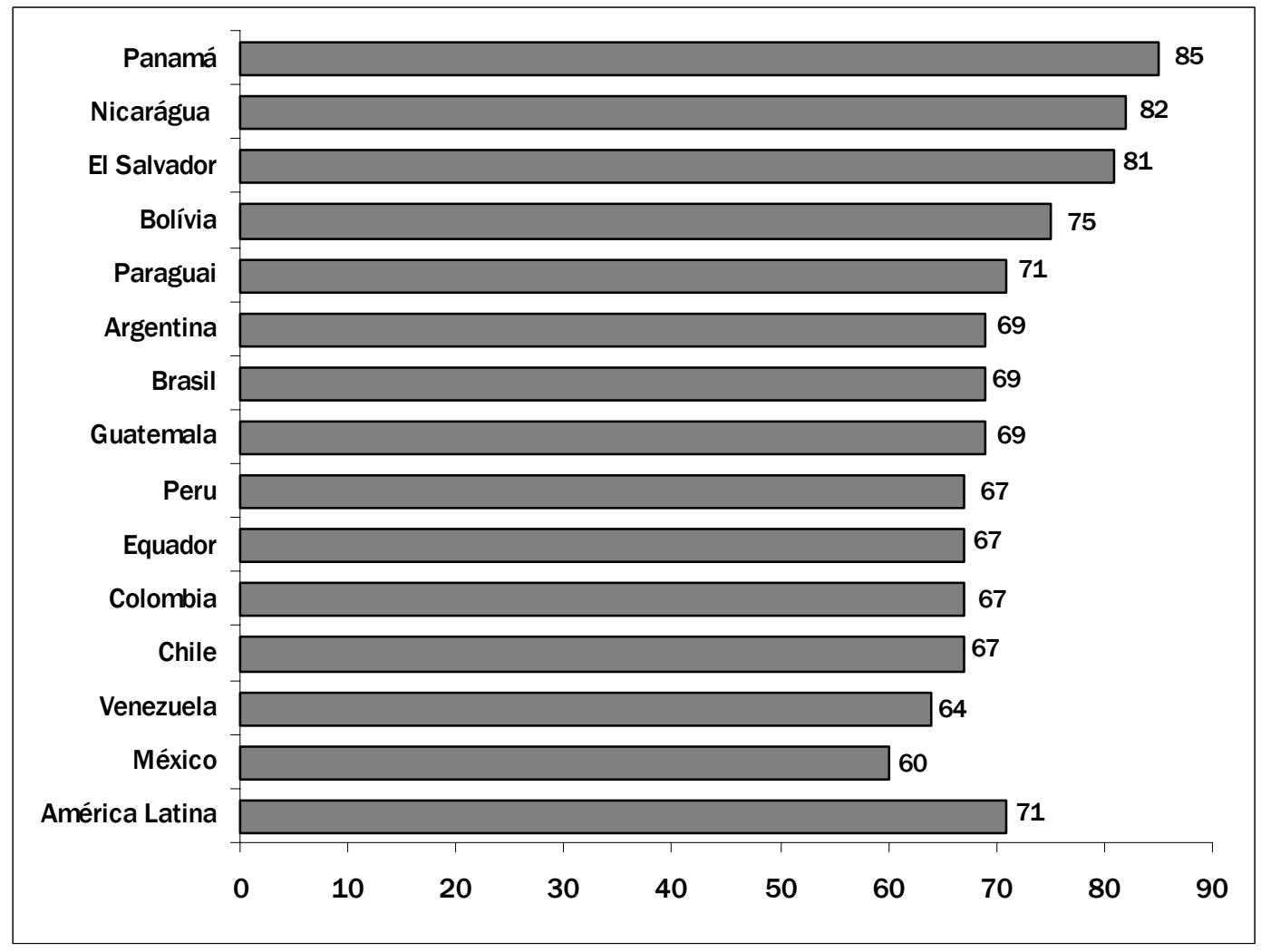

Fonte: Latinobarómetro 2003, citado por Lagos (2004)

Pergunta: "Serviços públicos como água, eletricidade, foram privatizados. Considerando preço e qualidade, você diria que está muito mais satisfeito, mais satisfeito, menos satisfeito ou muito menos satisfeito do que você estava antes com esses serviços?" (\% respostas "muito menos satisfeito" e "menos satisfeito")

Como se pode observar, a insatisfação da opinião pública latino-americana com os programas de privatização é clara. A grande maioria dos latino-americanos considera que as privatizações não foram benéficas para o país e estão pessoalmente mais insatisfeitos com os serviços públicos após a privatização dos mesmos. Como mostra a Figura 3.2, as avaliações negativas sobre os programas de privatização aumentaram em 2003 em comparação com 2002. Em 2005, a insatisfação com os programas de privatização em toda a América Latina permaneceu em cerca de 70\% (DEMOCRACY, 2005). 
ANDREWS, C. W. Investigando a legitimidade.

Carrera, Checchi e Florio (2004) utilizaram os dados da pesquisa de opinião do Latinobarômetro para o ano de 2002 e diversas macro-variáveis relativas a 17 países latino-americanos e chegaram a algumas conclusões importantes sobre os efeitos das privatizações na América Latina sobre a opinião pública. Eles observaram que os pobres - especialmente com educação superior - eram os mais insatisfeitos com as privatizações. A insatisfação também foi maior nos países que implementaram programas de privatização de forma muito rápida e onde foram aplicados choques macroeconômicos em um contexto de alta desigualdade social. A recomendação que os autores apresentaram para a continuidade dos programas de privatização na América Latina foi a seguinte:

\footnotetext{
"Podemos sintetizar nossos resultados em uma "receita" para uma privatização bem-sucedida: em primeiro lugar, escolha um país em que o número de pessoas que se auto-identificam com em condição [econômica] ruim ou muito ruim seja mínimo, portanto implicando uma desigualdade de renda moderada; em segundo lugar, faça com que as pessoas se acostumem com a privatização - máximo possível, adotando uma estratégia gradual (melhor privatizar aos pedaços do que de uma vez só); em terceiro, escolha uma fase de expansão [da economia], quando o crescimento da produção compensará outros choques adversos; quarto lugar, evite a privatização de serviços de utilidade pública, especialmente nos lugares em que a condição precária da classe média faz com que a percepção das conseqüências da privatização sejam mais agudas; quinto e por último, torça para que os rendimentos da privatização exerçam um impacto positivo na arrecadação do Estado [...]" (CARRERA et al., p. 27).
}

Por mais razoáveis que essas recomendações possam parecer, dificilmente as condições propostas pelos autores poderão ser atendidas na América Latina, especialmente a distribuição da renda. Quanto à recomendação de que se deve evitar a privatização de serviços públicos, ela é, ao mesmo tempo, extemporânea e fora de contexto: o principal "alvo" das privatizações na América Latina foram justamente os serviços de utilidade pública. Cabe lembrar que as principais recomendações do "Consenso de Washington" para os governos latino-americanos no momento em que enfrentavam a crise da dívida externa foram o "encolhimento" do Estado por meio de privatizações e o corte dos investimentos públicos (PORTELLA FILHO, 1994). Talvez a única recomendação apresentada por Carrera et al. (op. cit.) que talvez ainda possa ser seguida pelos governos latino-americanos - ainda que isso implique considerável dose de cinismo - seria manter o nível de 
educação da população o mais baixo possível, especialmente entre os pobres, evitando-se, assim, a emergência de opiniões críticas sobre a privatização.

No que se refere à análise no nível micro, os resultados mostram que não é possível identificar por meio das quatro variáveis do WVS a existência de uma "síndrome de cultura política" seja na direção do setor público seja na direção do setor privado. Os resultados das correlações bivariadas (correlações de Spearman) são apresentados na Tabela 2. Uma vez que escalas das variáveis V142 e V144 foram invertidas, a presença de correlações negativas indica divergência entre as variáveis, enquanto as correlações positivas indicam que há convergência. Como se pode observar, todas as correlações significativas que envolvem a variável sobre a responsabilidade na provisão de necessidades básicas (V143) foram negativas, demonstrando uma divergência na interação entre esta variável e as demais. Nos casos da República Tcheca e da Alemanha, a divergência entre a variável responsabilidade e a variável propriedade de negócios (V142) chega a ser moderada, com índices de Spearman de -0,417 e -0,373 respectivamente. As correlações positivas mais altas são observadas entre as variáveis sobre propriedade de negócios (V142) e competição (V144) na República Tcheca, Alemanha e nos Estados Unidos, correspondendo aos índices de Spearman de 0,394, 0,437 e 0,443, respectivamente. As demais correlações significativas e positivas são fracas.

Cabe destacar que, embora a correlação entre as variáveis relativas à propriedade dos negócios (V142) e competição (144) seja moderada em três países, para outros seis as correlações positivas são muito fracas. Nesse sentido, nem mesmo esse par de variáveis mostra-se indicado para avaliar o grau de legitimidade do setor privado vis-à-vis o setor público em estudos comparados. De um modo geral, os resultados indicam que as quatro variáveis do WVS carecem de uma clara consistência interna. Assim sendo, não devem ser considerados como uma única dimensão, capaz de identificar a existência de uma "síndrome de cultura política" que se refira ao setor público e ao setor privado. 
ANDREWS, C. W. Investigando a legitimidade.

Tabela 2

Correlações de Spearman relativas às orientações públicas versus privadas

\begin{tabular}{|c|c|c|c|c|}
\hline \multicolumn{2}{|c|}{ PAÍSES / VARIÁVEIS } & \multirow{2}{*}{$\begin{array}{c}\begin{array}{c}\text { Propriedade de } \\
\text { negócios }\end{array} \\
*\end{array}$} & \multirow{2}{*}{$\begin{array}{c}\text { Responsabilidade } \\
-0,237\end{array}$} & \multirow{2}{*}{$\begin{array}{c}\text { Competição } \\
0,092\end{array}$} \\
\hline \multirow{3}{*}{ ARGENTINA } & Renda & & & \\
\hline & Propriedade de negócios & & * & 0,201 \\
\hline & Responsabilidade & & & * \\
\hline \multirow{3}{*}{ BRASIL } & Renda & * & $-0,123$ & * \\
\hline & Propriedade de negócios & & $-0,079$ & 0,089 \\
\hline & Responsabilidade & & & * \\
\hline \multirow{3}{*}{ CHILE } & Renda & * & $-0,381$ & $-0,071^{a}$ \\
\hline & Propriedade de negócios & & * & 0,244 \\
\hline & Responsabilidade & & & 0,151 \\
\hline \multirow{3}{*}{ REP. CHECA } & Renda & 0,205 & $-0,241$ & 0,136 \\
\hline & Propriedade de negócios & & $-0,417$ & 0,394 \\
\hline & Responsabilidade & & & $-0,374$ \\
\hline \multirow{3}{*}{ POLÔNIA } & Renda & $0,069^{a}$ & * & $0,069 a$ \\
\hline & Propriedade de negócios & & $-0,268$ & 0,215 \\
\hline & Responsabilidade & & & $-0,171$ \\
\hline \multirow{3}{*}{ FED. RUSSA } & Renda & $0,053^{a}$ & * & 0,130 \\
\hline & Propriedade de negócios & & $-0,277$ & 0,253 \\
\hline & Responsabilidade & & & $-0,195$ \\
\hline \multirow{3}{*}{ FINLÂNDIA } & Renda & 0,102 & $-0,145$ & 0,123 \\
\hline & Propriedade de negócios & & $-0,327$ & 0,289 \\
\hline & Responsabilidade & & & $-0,238$ \\
\hline \multirow{3}{*}{$\begin{array}{c}\text { ALEMANHA * } \\
*\end{array}$} & Renda & & & \\
\hline & Propriedade de negócios & & $-0,373$ & 0,437 \\
\hline & Responsabilidade & & & $-0,347$ \\
\hline \multirow{3}{*}{ EUA } & Renda & * & $-0,272$ & * \\
\hline & Propriedade de negócios & & $-0,147$ & 0,443 \\
\hline & Responsabilidade & & & $-0,193$ \\
\hline
\end{tabular}

Apresentados os valores significantes a 0,01, exceto para (a), significante a 0,05 (2-tailed)

*Não significante.

**Dados não disponíveis para a variável relativa à renda (V141).

Fonte: European Values Study Group and World Values Survey Association (2004) 


\section{Considerações finais}

Os resultados da análise das variáveis do World Values Survey que tratam das atitudes do público em relação ao papel do Estado e do mercado para o bem-estar de indivíduos mostraram que não é possível identificar uma "síndrome de cultura política" relativa a esse aspecto. No nível macro, a análise não indicou uma clara orientação público/privado. Os dados permitem argumentar que existiria um consenso quanto aos benefícios da competição e, por extensão, à economia de mercado. Isso, no entanto, parece não se aplicar a aspectos específicos das reformas pró-mercado, como é o caso das privatizações na América Latina (LAGOS, 2004).

No nível micro, devido à falta de consistência interna entre as variáveis e de uma aparente relação das variáveis com a tipologia dos "três mundos" de Esping. Andersen, nossa análise confirma os resultados já obtidos por Mehrtens III (2004). Em outras palavras, não é possível discriminar entre os três tipos de Estado de bem-estar social por meio de pesquisas de opinião, ou, pelo menos, não por meio das variáveis do WVS.

Embora este artigo tenha abordado um aspecto da legitimidade que difere em muitos aspectos da chamada "legitimidade política", os resultados encontrados apresentam um interessante paralelo com as observações feitas por Seligson et al. (2006). Esses autores notaram que dimensões muito abstratas, como "apoio à comunidade política" e "princípios centrais do regime", têm um patamar de respostas positivas muito alto. Em uma escala de sete pontos ajustada para valores de 0 a 100, a média do grupo de variáveis da primeira e segunda dimensões foi de 90,83 e 79, 35, respectivamente. De maneira análoga, podemos dizer que os valores agregados altos para a variável "competição" (V144) representam um fenômeno semelhante, pois a média do percentual de avaliação positiva nos nove países foi de $74,28 \%$. Os autores também notaram que "[...] à medida que aumenta a especificidade da referência às instituições e atores e situações concretas, as médias para cada conjunto de itens das dimensões caem para níveis muito mais baixos [...]" (p. 26). Aparentemente, questões genéricas e abstratas podem ser ainda mais susceptíveis ao fenômeno da aquiescência, isto é, a tendência para respostas positivas a questões de surveys baseadas no formato "concordo/discordo" (BILLIET; CAMBRÉ; WELKENHUYSEN-GYBELS, 2002).

De todo o modo, o maior problema pertinente as quatro variáveis do WVS parece ser mesmo sua interpretação, dado o seu caráter genérico e abstrato. Além de serem de difícil interpretação pelos respondentes, é preciso lançar mão de pressupostos adicionais para relacioná-las à legitimidade do setor privado vis-à-vis o setor público. Por esse motivo, as pesquisas de opinião realizadas em diferentes 
ANDREWS, C. W. Investigando a legitimidade.

países exigem cuidados especiais na formulação de variáveis e na elaboração de questionários (HARKENESS, 1999; HARKENESS, 2004).

Também é preciso levar em consideração questões metodológicas mais amplas. Embora pesquisas de opinião e o uso de métodos estatísticos sejam valiosos instrumentos para o progresso do conhecimento na área de ciências sociais, os métodos qualitativos estão sendo cada vez mais lembrados como complementos necessários. Este é a opinião de Brady e Collier (2004), autores que têm uma larga experiência em estudos comparados. Esses autores contestaram os argumentos centrais de King, Keohane e Verba em Designing social inquiry: scientific inference in qualitative research (1994), livro que se tornou um clássico das ciências sociais ao propor que os estudos qualitativos deveriam seguir os mesmos princípios de inferência dos métodos quantitativos como estratégia para garantir o rigor e validade dos estudos sociais. Brady e Collier sustentam que os métodos qualitativos seguem princípios de investigação próprios e que não devem "mimetizar" os métodos quantitativos. Para esses autores, tanto a pesquisa qualitativa como a quantitativa são difíceis de serem bem feitas e o rigor analítico não é mais fácil de ser obtido com métodos quantitativos do que com métodos qualitativos. "A razão central porque tanto a pesquisa qualitativa como a quantitativa é difícil de se fazer bem é que qualquer estudo baseado em dados observacionais (isto é, nãoexperimentais) enfrenta o desafio fundamental da inferência que é eliminar explicações rivais" (BRADY e COLLIER, 2004, p. 10). Como pudemos observar aqui, quando as variáveis utilizadas em estudos quantitativos são abstratas e genéricas, a dificuldade de eliminação das explicações rivais se intensifica. Portanto, os estudos comparados, que têm como uma de suas principais fontes de informações surveys internacionais, poderiam ser muito beneficiados com uma maior atenção na formulação das variáveis. Tais estudos também seriam beneficiados de uma estratégia de investigação capaz de aliar métodos quantitativos e qualitativos.

\section{Referências Bibliográficas}

ALMOND, G. A.; VERBA, S. The civic culture. Princeton: Princeton University Press, 1963.

BILLIET, J.; CAMBRÉ, B.; WELKENHUYSEN-GYBELS, J. Equivalence of measurement instruments for attitude variables in comparative surveys, taking method effects into account: the case of ethnocentrism. In: FERLIGOJ, A.; MRVAR, A. (eds.). Developments in social science methodology. Ljubljana: FDV, 2002. (Metodološki zvezki, 18). Disponível em: <http://mrvar.fdv.uni-lj.si/pub/ mz/mz18/billet.pdf>. Acesso em: 10 jul. 2006. 
BOURDIEU, P. The social space and the genesis of groups. Theory and Society, v. 14, n. 6, p. $723-744,1985$.

BRADY, H.; COLLIER, D. (orgs.) Rethinking social inquiry: diverse tools, shared standards. Lanham, Rowman \& Littlefield, 2004.

BROADBENT, J.; LAUGHLIN, R. Evaluating the 'new public management' reforms in the UK: A constitutional possibility? Public Administration, v. 75, n. 3, p. 487-507, 1997.

BUNCE, V. Comparative democratization - big and bounded generalizations. Comparative Political Studies, v. 33, n. 6-7, p. 703-734, 2000.

CARRERA, J.; CHECCHI, D.; FLORIO, M. Privatization discontent and its determinants: evidence from Latin America. Trabalho apresentado 60TH IIPF CONGRESS, Milão, 23 a 26 de agosto, 2004. Disponível em: <http://www.economia.unimi.it/pubb/wp203.pdf>. Acesso em 16 de maio de 2005.

COHN, D. Creating crises and avoiding blame: the politics of public service reform and the new public management in Great Britain and the United States. Administration \& Society, v. 29, n. 5, p. 584-616, 1997.

DEMOCRACY's ten year rut. The Economist, London. Disponível em: <http://www.economist.com/PrinterFriendly.cfm?story_id=5093522>. Acesso em: 31 out. 2005.

EUROPEAN VALUES STUDY GROUP AND WORLD VALUES SURVEY ASSOCIATION. European and world values surveys four-wave integrated data file, 1995-2000, v. 4. Produtores dos arquivos agregados: Análisis Sociológicos Económicos y Políticos (ASEP) and JD Systems (JDS), Madrid, Spain/Tilburg University, Tilburg, The Netherlands. Data Files Suppliers: Analisis Sociologicos Economicos y Politicos (ASEP) and JD Systems (JDS), Madrid, Spain/Tillburg University, Tillburg, The Netherlands/ Zentralarchiv fur Empirische Sozialforschung (ZA), Cologne, Germany. Distribuidores de arquivos agregados: Análisis Sociológicos Económicos y Políticos (ASEP) e JD Systems (JDS), Madrid, Spain/Tillburg University, Tilburg, The Netherlands/Zentralarchiv fur Empirische Sozialforschung (ZA) Cologne, Germany, 2004.

ESPING-ANDERSEN, G. The three worlds of welfare capitalism. Cambridge: Polity Press, 1990.

FUKUYAMA, F. The end of history and the last man. Harmondsworth: Penguin, 1992.

FINE, B. Social capital: "The World's Bank fungible friend". Journal of Agrarian Change, v. 3, n. 4, p. 586-603, 2003. 
GOW, J. I.; DUFOUR, C. Is the new public management a paradigm? Does it matter?. International Review of Administrative Sciences, v. 66, n. 4, p. 573-597, 2000.

GRAHAM, C.; SUKHTANKAR, S. Does economic crisis reduce support for markets and democracy in Latin America? Some evidence from surveys of public opinion and well being. Journal of Latin American Studies, v. 36, p. 349-377, 2004.

HABERMAS, J. The theory of communicative action: reason and rationalization of society. v. 1 . Boston: Beacon Press, 1984.

. Between facts and norms: contributions to a discourse theory of law and democracy. Cambridge: MIT Press, 1998.

HARKNESS, J. A. In pursuit of quality: issues for cross-national survey research. International Journal of Social Research Methodology, v. 2, n. 2, 1999.

HARKNESS, J. Measurement and comparability in cross-national health surveys used to inform policy decisions. In: MacGREGOR, S. (org.). The impact of social science research on social policy: governance and management. Cross-National Research Papers Seventh Series, European Cross-National Research and Policy. Disponível em: <http://www.xnat.org.uk/>. Acesso em 22 jun. 2006.

HUBER, E.; SOLT, F. Successes and failures of neoliberalism. Latin American Research Review, v. 39, n. 3, p. 150-162, 2004.

HUNTINGTON, S. The third wave: democratization in the late twentieth century. Norman: University of Oklahoma Press, 1991.

INGLEHART, R. The renaissance of political culture. American Political Science Review, v. 82, p. 1203-1230, 1988.

INGLEHART, R.; WELZEL, C. Political culture and democracy: Analyzing cross-level linkages. Comprarative Politics (no prelo). Disponível em:

<http://www.worldvaluessurvey.org/Upload/5_Ecolfal3.pdf>. Acesso em: 10 abr. 2004.

INTERNATIONAL MONETARY FUND - IMF. The IMF's Enhanced Structural Adjustment Facility (ESAF): Is It Working? Disponível em:

<http://www.imf.org/external/pubs/ft/esaf/exr/index.htm>. Acesso em: 19 fev. 2005. 
KING, G.; KEOHANE, R.; VERBA, S. Designing social inquiry: scientific inference in qualitative research. Princeton: Princeton University Press, 1994.

LAGOS, M. Latinobarómetro 1996 - 2003. Focus Eurolatino Program, European Commission Directorate General for Foreign Relations, Canning House June 28 ${ }^{\text {th }}, 2004$.

LATINOBARÓMETRO. Latinobarómetro: opinion latinoamericana. Disponível em: <http://www.latinobarometro.org/>. Acesso em: $1^{\circ}$ de mai. 2005. [s.d.]

LYNN, L. E. The new public management: how to transform a theme into a legacy. Public Administration Review, v. 58, n.3, p. 231-237.

MANNING, N. "The legacy of the New Public Management in developing countries". International Review of Administrative Sciences, v. 67, n. 2, p. 297-312, 2001.

MAOR, M. The paradox of managerialism. Public Administration Review, v. 59, n. 1, p. 5-18, 1999.

MEHRTENS III, J. F. Three worlds of public opinion? Values, variation, and the effect on social policy. Public Opinion Research, v. 16, n. 2, p. 115-143, 2004.

NELLIS, J.; MENEZES, R.; LUCAS, S. Privatization in Latin America: the rapid rise, recent fall, and continuing puzzle of a contentious economic policy. Policy Brief, v. 3, n. 1, p. 1.8, 1999.

PARKER, D.; KIRKPATRICK, C. Privatization in developing countries: a review of the evidence and the policy lessons. Centre on Regulation and Competition, Institute for Development Policy and Management (Working Papers Series, Paper n. 55). Disponível em: <http://www.competition. regulation.org.uk/wpdl5099/wp55.pdf>. Acesso em: 19 fev. 2005.

PORTELLA FILHO, P. O ajustamento na América Latina: crítica ao Consenso de Washington. Lua Nova, n. 32, p. 101-131, 1994.

PINHEIRO, M. A Argentina que reage: Lavahna desafia mercado e aperta o cerco contra capitais especulativos. Carta Capital, São Paulo, 22 jun. 2005.

POLLITT, C. The new manageralism and the public services: the anglo american experience. Oxford: Basil, 1990. 
PONTHIEUX, S. The concept of social capital: a critical review. $10^{\text {TH }}$ ACN CONFERENCE, Paris, 21.23 jan. 2004. Disponível em:

<http://www.insee.fr/en/nom_def_met/colloques/acn/colloque_10/ponthieux.pdf>. Acesso em: 10 abr. 2006.

POWELL, M.; BARRIENTOS, A. Welfare regimes and the welfare mix. European Journal of Political Research, v. 43, p. 83-105, 2004.

PUTNAM, R.; LEONARDI, R.; NANETTI, R. Making democracy work: civic traditions in modern Italy. Princeton: Princeton University Press, 1993.

SELIGSON, M. The renaissance of political culture or the renaissance of the ecological fallacy? Comparative Politics, v. 34, n. 3, p. 273-292, 2002.

SELIGSON, M; BOOTH, J. A.; GOMÉZ B., M. Os contornos da cidadania crítica: explorando a legitimidade democrática. Opinião Pública, v. 12, n. 1, p. 1-37, 2006.

SIL, R.; CHEN, C. State legitimacy and the (in)significance of democracy in post-communist Russia. Europe-Asia Studies, v. 56, n. 3, p. 347-368, 2004.

SINGER, H. W. Editorial: the golden age of keynesian consensus - the pendulum swings back. World Development, v. 25, n. 3, p. 293-295, 1997.

WEYLAND, K. Threats to Latin America's market model? Political Science Quarterly, v. 119, n. 2, p. 291-313, 2004.

WORLD BANK. About privatization. Disponível em:

<http://rru.worldbank.org/PapersLinks/Privatization-Strategy/>. Acesso em: 19 fev. 2005.

Recebido para publicação em maio de 2006. Aprovado para publicação em setembro de 2006. 